\title{
Smart Sensor Systems for Aerospace Applications: From Sensor Development to Application Testing
}

\author{
G. W. Hunter ${ }^{\mathrm{a}}$, J. C. Xu $\mathrm{u}^{\mathrm{a}}$, L. K. Dungan ${ }^{\mathrm{b}}$, B. J. Ward ${ }^{\mathrm{c}}$, S. Rowe ${ }^{\mathrm{c}}$, J. Williams ${ }^{\mathrm{c}}$, D. B. \\ Makel $^{\mathrm{c}}$, C.C. Liu ${ }^{\mathrm{d}}$, and C. W. Chang ${ }^{\mathrm{e}}$ \\ a) NASA Glenn Research Center, Cleveland, OH 44135, USA \\ b) NASA Johnson Space Center, Houston, TX 77058, USA \\ c) Makel Engineering, Inc., Chico, CA 95973, USA \\ d) Case Western Reserve University, Cleveland, OH 44106, USA \\ e) ASRC Aerospace Corporation, Inc., Cleveland, OH 44135, USA
}

The application of Smart Sensor Systems for aerospace applications is a multidisciplinary process consisting of sensor element development, element integration into Smart Sensor hardware, and testing of the resulting sensor systems in application environments. This paper provides a cross-section of these activities for multiple aerospace applications illustrating the technology challenges involved. The development and application testing topics discussed are: 1) The broadening of sensitivity and operational range of silicon carbide (SiC) Schottky gas sensor elements; 2) Integration of fire detection sensor technology into a "Lick and Stick" Smart Sensor hardware platform for Crew Exploration Vehicle applications; 3) Extended testing for zirconia based oxygen sensors in the basic "Lick and Stick" platform for environmental monitoring applications. It is concluded that that both core sensor platform technology and a basic hardware platform can enhance the viability of implementing smart sensor systems in aerospace applications.

\section{Introduction}

Aerospace applications require a range of chemical sensing technologies to monitor conditions in both space vehicle environments and in aircraft or spacecraft operations. The ability to produce microsensor platforms that can be tailored to measure a range of species has been an ongoing technology direction of this group. From these basic platforms, a range of sensor elements can be fabricated and tailored to meet the needs of a range of applications. Combined with that effort has been the development of miniaturized hardware and software systems that can be implemented in aerospace applications. The approach is to make Smart Sensor Systems, i.e., systems which include a microprocessor, signal conditioning, data processing, power conditioning, heater control, and communication in a compact structure. The overall approach is to make "Lick and Stick" technology which combines this functionality in a system near the size of a postage stamp that can be placed, like a postage stamp, wherever needed in a vehicle [1-2].

A core capability has been developed to measure a range of selected chemical species which address the needs of a number of aerospace applications. For example, in the detection of fire conditions aboard aircraft and spacecraft, the measurement of species such as carbon monoxide (CO), carbon dioxide $\left(\mathrm{CO}_{2}\right)$, oxygen $\left(\mathrm{O}_{2}\right)$, and hydrogen/hydrocarbons $\left(\mathrm{H}_{2} / \mathrm{H}_{\mathrm{x}} \mathrm{C}_{\mathrm{y}}\right)$ significantly enables an improved understanding of the en- 
vironment and earlier detection of hazardous events. Likewise, the ability to measure some of the same chemical species such as, $\mathrm{CO}, \mathrm{CO}_{2}, \mathrm{O}_{2}$, nitrogen oxides $\left(\mathrm{NO}_{\mathrm{x}}\right)$, and, again, $\mathrm{H}_{2} / \mathrm{H}_{\mathrm{x}} \mathrm{C}_{\mathrm{y}}$ is necessary in jet engine emission monitoring. Such $\mathrm{H}_{2} / \mathrm{H}_{\mathrm{x}} \mathrm{C}_{y}$ sensors, which could also measure hydrazine, are also necessary for other aerospace applications such as fuel leak detection or environmental monitoring. However, the operating requirements for a sensor in fire detection, engine emissions monitoring, fuel leak detection, and environmental monitoring are significantly different. Thus, production of sensor platform technology which can be flexibly tailored to meet broad application needs and integrated into Smart Sensor Systems is required. One sensor platform is the Schottky diode structure, while other platforms include solid state electrochemical cells and resistors [12]. From the Schottky diode platform, a range of sensor elements can be fabricated by selection of the basic materials and material combinations.

These sensor elements must be packaged and integrated with hardware and software e.g., Smart Sensor Systems, in order to be implemented into flight applications. Considerations related to application requirements and environments must be considered during the design phase of the Smart Sensor Systems. Fundamental hardware design considerations include minimizing size, weight, power consumption; accommodating a range of possible voltage inputs; and multiple wired and/or wireless communication interfaces. Operational considerations such as the sensor operating temperature, capability to withstand changes in the sensor environment, and durability of the sensor system have strong roles to play in the viability of a sensor system to meet the requirements of a given application. If the sensor is battery powered, battery life is a key requirement that greatly impacts the deployability of the system. Further, extensive testing of the resulting sensor systems in relevant environments for extended duration to determine the sensor life is a necessary step prior to long-term implementation. These tests are not simply of the sensor element or supporting hardware, but of the complete end-to-end system. Thus, our Smart Sensor System development has been driven by the need to broaden the operational capabilities of the various sensor platforms; to integrate sensors with hardware appropriate for implementation in aerospace applications; and to test the complete sensor systems in relevant environments over the expected life of the sensors.

This paper provides three examples of this development at different stages of the process: 1) The broadening of sensitivity and operational range of a silicon carbide (SiC) Schottky diode sensor element; 2) Efforts to decrease the size of an existing fire detection system through integration into a "Lick and Stick" platform, thereby increasing its viability for inclusion in aerospace applications; and 3) The extended testing for possible implementation of the zirconia $\left(\mathrm{ZrO}_{2}\right)$ based oxygen sensor integrated into the "Lick and Stick" platform for environmental monitoring applications. The relevance of each of these examples to the broader program of maturing Smart Sensor Systems for aerospace applications will be highlighted. It is concluded that the development and application of Smart Sensor Technology is both a multidisciplinary and multistage project involving different technological capabilities and requirements for each stage of the process.

\section{Sensor Element Development: Silicon Carbide Gas Sensor}

An example of adapting a sensor platform for a wider application range is that of the $\mathrm{SiC}$ gas sensor system. The basic Schottky diode gas sensor platform is composed of a catalyst and a semiconductor with a possible thin insulating layer ( $\sim 50 \AA)$ in-between. 
Building from the basic Schottky diode sensor platform, the use of SiC as the semiconductor allows for high temperature applications not achievable with conventional silicon based devices. Previously, SiC Schottky diode gas sensors have been operated by this group at temperatures typically above $400^{\circ} \mathrm{C}$ and used for hydrogen detection at the parts per million (ppm) level and above including in inert environments [1-3]. Although the $\mathrm{SiC}$ semiconductor has excellent high temperature performance, the sensitivity of the device can be limited by the reliability and stability of the interfaces between the SiC semiconductor and other layers of the device. High temperature reactions can lead to formation of silicides. These reactions lead to reduced sensitivity and disruptions of the device performance.

In order to prevent these reactions and possible sensor degradation, one approach is to deposit a controlled thickness of palladium oxide $\left(\mathrm{PdO}_{\mathrm{x}}\right)$ between the catalyst and the $\mathrm{SiC}$ [4]. Palladium oxide is chosen as a barrier layer due to its inertness and compatibility for inclusion in the Schottky diode structure. In this work, a palladium/palladium oxide/silicon carbide $\left(\mathrm{Pd} / \mathrm{PdO}_{\mathrm{x}} / \mathrm{SiC}\right)$ Schottky diode sensor design was investigated for its viability, including testing at room temperature, low hydrogen concentrations, and high temperatures. The remainder of this section discusses the fabrication and characterization of this sensor design.

The basic design of the $\mathrm{Pd} / \mathrm{PdO}_{\mathrm{x}} / \mathrm{SiC}$ Schottky diode sensing element is illustrated in Figure 1. Pd is the catalytic sensing metal layer, the substrate is $\mathrm{SiC}$, the barrier layer located between the substrate and sensing metal is $\mathrm{PdO}_{\mathrm{x}}$, and a backside contact. The sensor is fabricated using an n-type $\mathrm{SiC}$ wafer, with an n-type epilayer. The wafer is first prepared by cleaning, followed by sputter depositing titanium and nickel to form the backside contact. The front side of the wafer was patterned with a photoresist/mask pattern for liftoff deposition of $\mathrm{PdO}_{\mathrm{x}}$ and $\mathrm{Pd}$. Reactive sputter deposition of approximately $50 \AA$ of $\mathrm{Pd}$ in oxygen/argon gas leads to the $\mathrm{PdO}_{\mathrm{x}}$ barrier layer. Sputter deposition of $\mathrm{Pd}$ was used for the catalytic sensing layer ( 450 $\AA$ ) on top of this barrier layer [4]. A forward or reverse bias may be applied to the diode through the metal Pd layer causing forward or reverse current to flow. The $\mathrm{PdO}_{\mathrm{x}}$ barrier layer was thin enough such that tunneling can occur through this layer forming the Schottky diode structure.

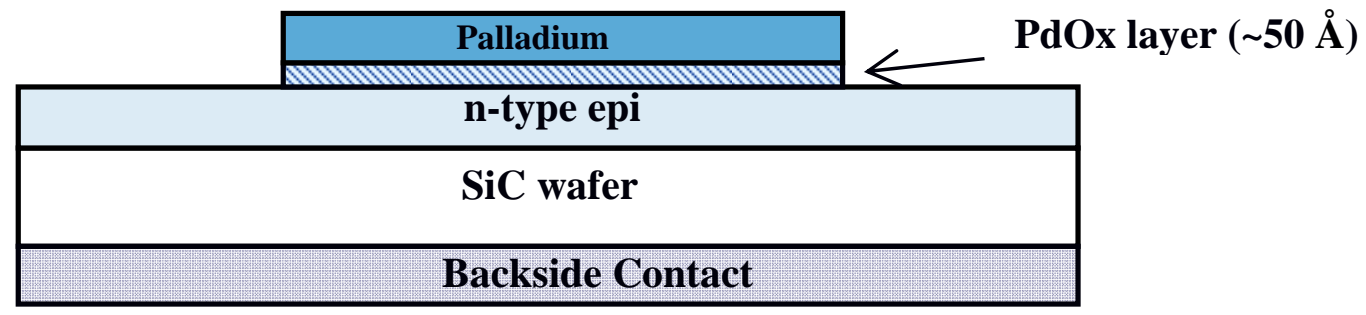

Figure 1. Illustration of the $\mathrm{Pd} / \mathrm{PdO}_{\mathrm{x}} / \mathrm{SiC}$ Schottky diode gas sensor. The catalyst (Pd) is located above barrier layer (PdOx) on the SiC substrate. The backside contact and gate form the two electrodes of the diode.

When $\mathrm{H}_{2}$ or $\mathrm{H}_{\mathrm{x}} \mathrm{C}_{\mathrm{y}}$ gases make contact with the Pd catalytic layer, they dissociate yielding atomic hydrogen. The resulting hydrogen is adsorbed into this Pd layer forming a dipole layer at the $\mathrm{Pd} / \mathrm{PdO}_{\mathrm{x}}$ interface causing a change in the diode electrical properties that varies with the hydrogen concentration. The $\mathrm{H}_{2} / \mathrm{H}_{\mathrm{x}} \mathrm{C}_{\mathrm{y}}$ concentration can thus be measured by detecting this change in the current for a given bias voltage of the diode. 
However, these effects are temperature dependent and the operation of the sensor depends on a range of operational parameters. The sensitivity and operational range of this sensing structure was investigated with the objective of understanding its use in a range of possible applications. Highlights of this characterization follow in the remainder of this section.

A sweep of the bias voltage and associated response at room temperature in both air and hydrogen environments is shown for the $\mathrm{Pd} / \mathrm{PdO}_{\mathrm{x}} / \mathrm{SiC}$ Schottky diode in Figure 2. This current-voltage plot (I-V) shows the sensor current response across the voltage range from $-10 \mathrm{~V}$ to $+4 \mathrm{~V}$ (both forward and reverse bias). The sensor current in hydrogen is higher than that in air and an operating voltage was chosen to maximize the sensor current response to hydrogen as based on these I-V curves. From data such as Figure 2, the use of $0.8 \mathrm{~V}$ was chosen at room temperature as a viable measurement voltage to maximize sensor response in the exponential portion of the forward bias direction. This optimum voltage varies with temperature.

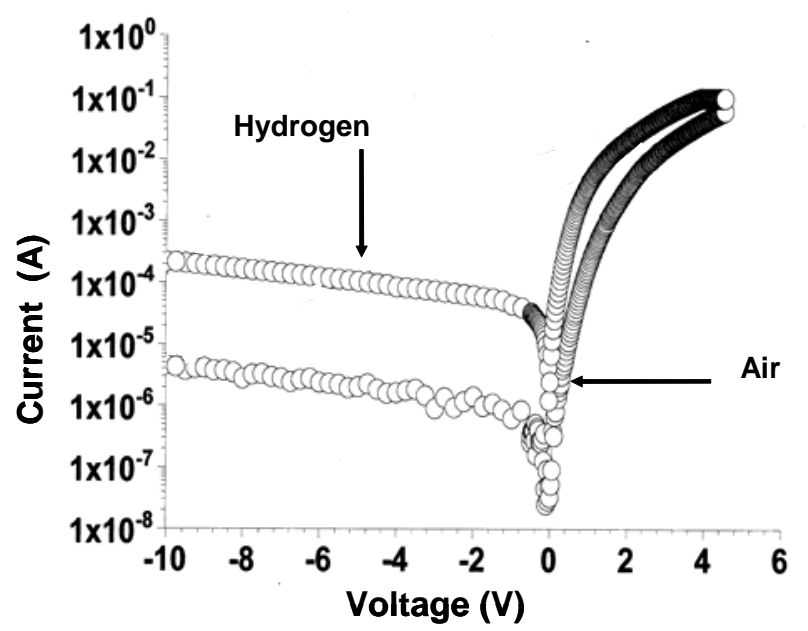

Figure 2. Plots of $\mathrm{Pd} / \mathrm{PdO}_{\mathrm{x}} / \mathrm{SiC}$ sensor current response in air and hydrogen environments versus bias voltage across the diode at room temperature.

Figure 3 shows the output current of the sensor biased at this $0.8 \mathrm{~V}$ at room temperature for the range of $20 \mathrm{ppm}$ to $5000 \mathrm{ppm}$ hydrogen. The sensor demonstrated a strong response from $20 \mathrm{ppm}$ to $0.5 \% \mathrm{H}_{2}$. Subsequent testing, however, suggests that the detection range of the sensor at room temperature was limited to near the one ppm range. Further, operation of this Pd sensor at this temperature range above $500 \mathrm{ppm}_{2}$ was limited by the fact that Pd can undergo a phase change at higher concentrations of $\mathrm{H}_{2}$ [1-2]. These tests do not explore the higher concentration limit for this sensor structure at this temperature to avoid damaging the diode. Thus, at room temperature this sensor structure demonstrates the capability of measuring $\mathrm{H}_{2}$ from the concentration range of $\sim 1 \mathrm{ppm}$ to at least $0.5 \%$.

Testing occurred to determine the detection limit of this sensor structure to lower concentration ranges of hydrogen. It was found that response at near room temperature did not completely optimize sensitivity to hydrogen. Rather, moderately elevating the temperature improved the low concentration sensitivity. Figure 4 shows the current output of the sensor when tested at $180^{\circ} \mathrm{C}$ and biased at $0.45 \mathrm{~V}$. The sensor was tested at $180^{\circ} \mathrm{C}$ with emphasis on the concentration range below $1.25 \mathrm{ppm}$. Figure 4 shows that 
the sensor is capable of sensing $\mathrm{H}_{2}$ as low as $0.25 \mathrm{ppm}$, or 250 part per billion (ppb) at this bias voltage. Thus, this sensor is shown to sense $\mathrm{H}_{2}$ as low as $250 \mathrm{ppb}$ demonstrating a broad range of detection capability using this basic sensor structure.

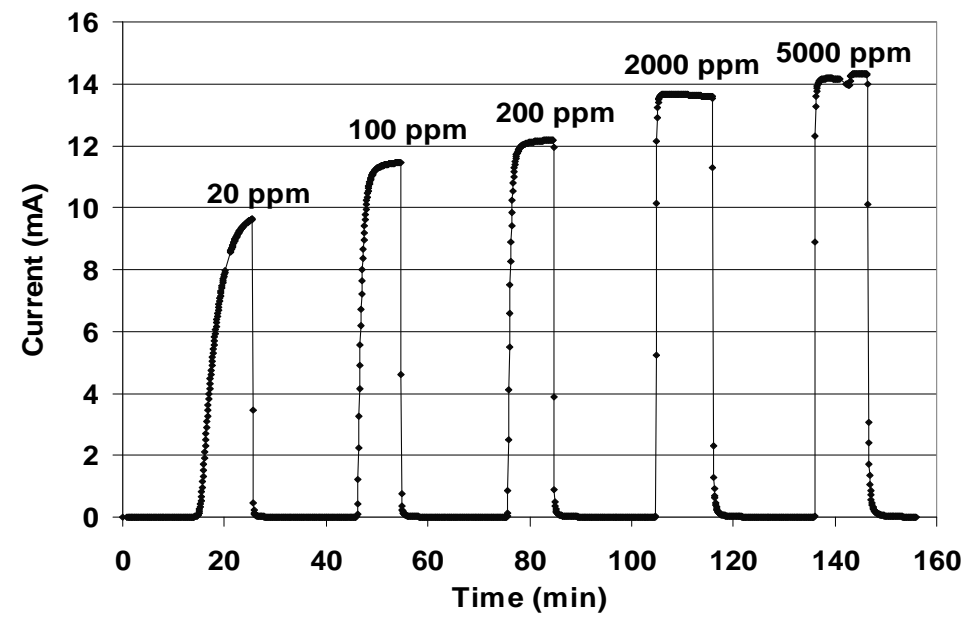

Figure 3. The output current of $\mathrm{Pd} / \mathrm{PdO}_{\mathrm{x}} / \mathrm{SiC}$ sensor biased at $0.8 \mathrm{~V}$ at $23^{\circ} \mathrm{C}$. Sensor was exposed to differing hydrogen concentrations in nitrogen with exposure to air to reestablish the baseline in between each hydrogen exposure.

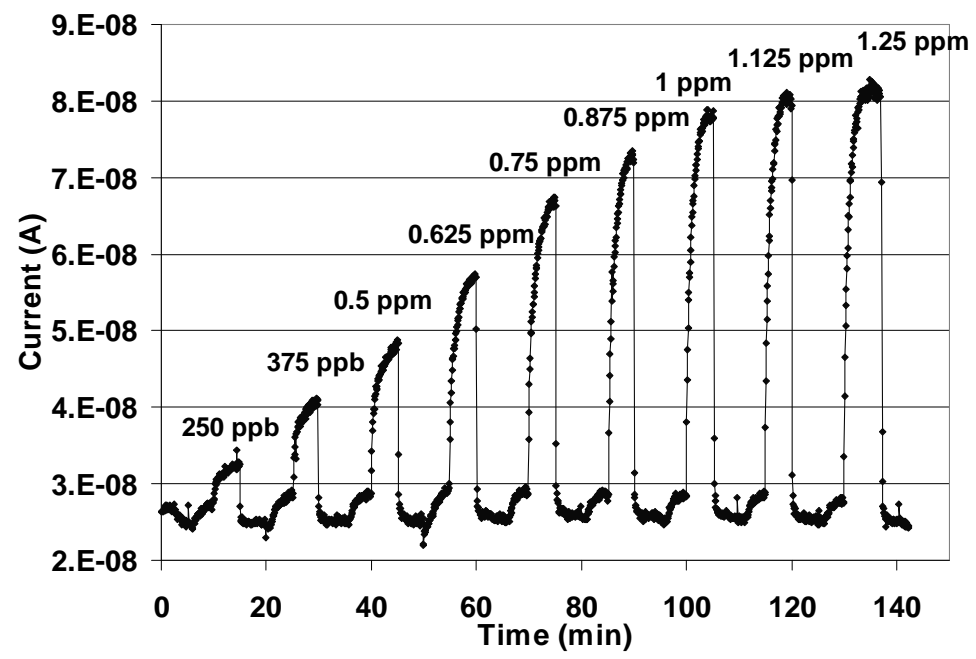

Figure 4. Plot of output current of the $\mathrm{Pd} / \mathrm{PdO}_{\mathrm{x}} / \mathrm{SiC}$ sensor biased at $0.45 \mathrm{~V}$ at $180^{\circ} \mathrm{C}$. Sensor was exposed to different hydrogen concentrations in nitrogen with exposure to air and then nitrogen in between each hydrogen exposure. This data shows that the sensor can be optimized to detect hydrogen concentration as low as $250 \mathrm{ppb}$.

Finally, testing occurred to determine the durability of this design for long-term operation at higher temperatures [4]. Figure 5 shows the long-term response of this sensor structure at $450^{\circ} \mathrm{C}$ at $1 \mathrm{~V}$ for over 1400 hours to $0.5 \% \mathrm{H}_{2}$ in $\mathrm{N}_{2}$. While there was a change in response in approximately the first 50 hours of heating, the sensor subsequently stabilized and consistently gave a strong response to $0.5 \% \mathrm{H}_{2}$. Other work (not shown) previously demonstrated the ability of this sensor to measure hydrocarbons such as propylene at these temperatures [4]. Thus, it is suggested that the use of $\mathrm{PdO}_{\mathrm{x}}$ between the catalytic metal and the $\mathrm{SiC}$ is a highly viable approach to stabilizing the Schottky diode structure at higher temperatures. Current activities are under way to further modify this sensor 
structure for the measurement of not only hydrogen or hydrocarbons, but also nitrogen oxides. This combines the basic platform $\mathrm{SiC}$ structure with interface layers such as tungsten oxide to increase $\mathrm{NO}_{\mathrm{x}}$ sensitivity.

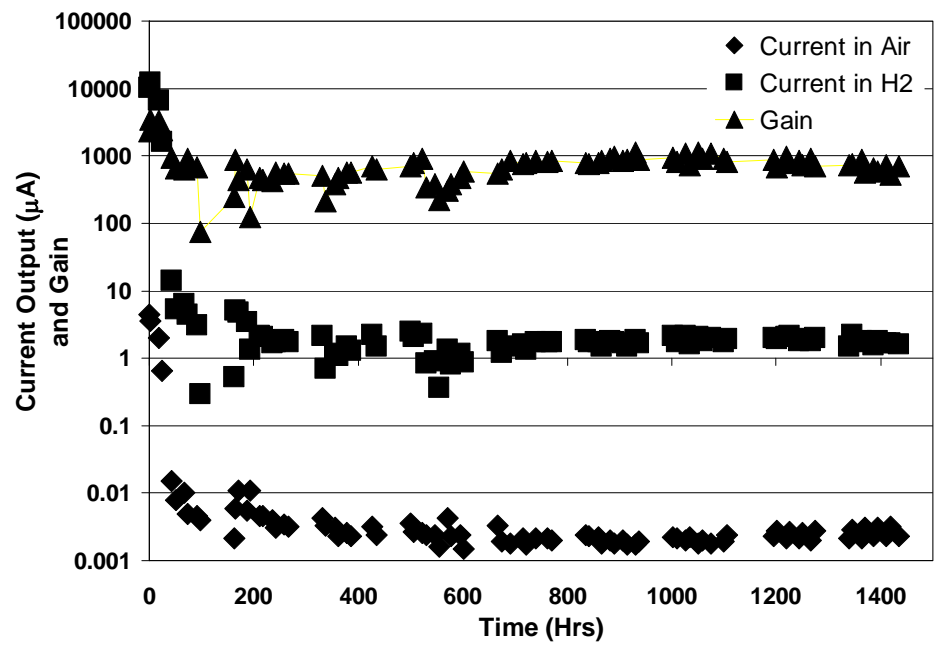

Figure 5. The $\mathrm{Pd} / \mathrm{PdO}_{\mathrm{x}} / \mathrm{SiC}$ Schottky diode gas sensor response at $450^{\circ} \mathrm{C}$ biased at $1 \mathrm{~V}$. Shown is the baseline current in air, current in $0.5 \%$ hydrogen in nitrogen, and the sensor gain (change in sensor signal/baseline signal). The sensor has nearly constant behavior throughout the extended test period after a break-in period [4].

In summary, this work examined one possible structure of the Schottky diode sensor platform: the $\mathrm{Pd} / \mathrm{PdO}_{\mathrm{x}} / \mathrm{SiC}$ Schottky diode. This basic sensing element has demonstrated high sensitivities and wide detection ranges, down to $5 \mathrm{ppm}$ at room temperature and 250 $\mathrm{ppb}$ at $180^{\circ} \mathrm{C}$, as well as the ability to operate at elevated temperatures (up to $450^{\circ} \mathrm{C}$ ). It can thus be used at room temperature without being heated to decrease power consumption or at elevated temperature $\left(450^{\circ} \mathrm{C}\right)$ for over 1400 hours if harsh environment applications are necessary. It operates without the need for oxygen and thus can operate in environments such as unpressurized space applications. Thus, from one sensor design, the choice of basic structure, measurement voltage, and operation temperature allows a significant broadening of sensitivity and operational range.

\section{Sensor System Level Development: Miniaturized Fire Detection System}

One area of application of a sensitive $\mathrm{H}_{2} / \mathrm{H}_{\mathrm{x}} \mathrm{C}_{\mathrm{y}}$ sensor is in the area of fire detection. Previous work in fire detection has targeted the development of a low false alarm fire detection system based on micro/nano sensor technology to address the problem of high false alarm rates for fire detection systems in the cargo bay of aircraft (as high as 200-1 depending on the study) [1-2,5]. The approach was to combine a range of very different sensor technologies tailored to minimize cross-sensitivity (orthogonal sensors) to measure a range of parameters and better understand the environment. The objective of this Multi-Parameter, Microsensor Fire Detection System (MMFDS) was to be able to accurately detect a fire without being triggered into a false alarm by such environmental parameters as dust or humidity. The MMFDS eliminated false alarms while consistently detecting fires in testing at the Federal Aviation Administration.

The basic MMFDS used for this aeronautics testing is shown in Figure 6. This includes multiple chemical sensors as well as a particulate sensor. This unit could be tai- 
lored for commercial applications depending on customer requirements; however, application of this unit for space applications requires significant modification directly related to the requirements of spaceflight operations. The reason for these modifications include: 1) Minimization of size, reduction of weight, and reduced power consumption for integration into space flight vehicles; 2) Optimization of sensor operating parameters to target likely chemical species and concentration ranges present in space operations; 3) Selection of parts and components compatible with space qualified parts listing, i.e., choosing parts which will work in a space radiation and extreme condition environments. Activities are under way to produce a Miniaturized Multiparameter Smart Space Fire Detection System for Crew Exploration Vehicle space applications using the sensors and low false alarm detection approach demonstrated by the MMFDS.

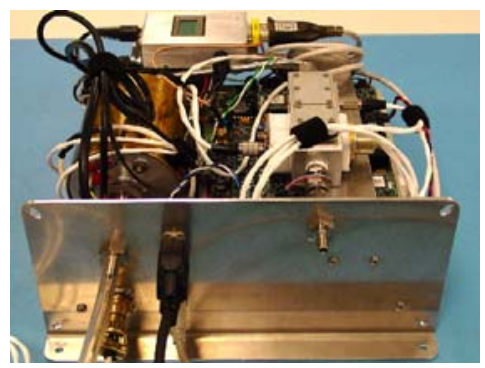

Figure 6. Prototype Multiparameter MicroSensor Based Low False Alarm Fire Detection System for Aeronautics Applications.

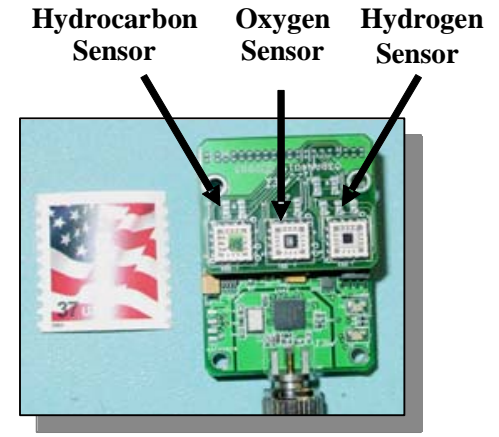

Figure 7. "Lick and Stick” Leak Detection System Platform. System includes multiple sensors, a microprocessor, as well as power and communication [7].

The fundamental approach used in this work is to base the Miniaturized Multiparameter Smart Space Fire Detection System on the "Lick and Stick" technology. The "Lick and Stick" platform has multiple sensors, a microprocessor, signal conditioning, and data processing. The presence of the microprocessor significantly enables the "smart" attributes of the hardware system and allows reprogramming of a range of functions. The design approach used for this "Lick and Stick" platform is to choose parts that are compatible with and can be qualified for space application. It can be configured for wireless or wired communication, or to work on an external power supply or be battery powered, or accommodate a range of sensor technology depending on the application. In general, this hardware platform is meant to be adaptable to a wide range of applications and be easily applied into an application environment. The basic "Lick and Stick" platform shown in Figure 7 with three sensors and has been under development for various applications for a considerable period of time [1,2,6-7]. For example, this tailored version of this "Lick and Stick" platform with a hydrogen sensor only is presently being qualified for Crew Launch Vehicle (CLV) implementation for leak detection.

Leveraging from activities such as the CLV “Lick and Stick" leak detection development and qualification, a Miniaturized Multiparameter Smart Space Fire Detection System is being designed and fabricated. The core electronics, interfaces, microprocessor, and overall hardware approach are being adapted from other hardware being flight qualified to produce this Miniaturized Multiparameter Smart Space Fire Detection System. In other words, the approach is to take advantage of the maturity of the core "Lick and Stick" system to decrease the development necessary for implementation of new hard- 
ware such as the Miniaturized Multiparameter Smart Space Fire Detection System into flight systems.

The present version of the Miniaturized Multiparameter Smart Space Fire Detection System is shown in Figure 8a. This system features four sensors for fire detection, two sensors to measure the environment for improved chemical species measurement accuracy, a small pump for air flow, and the basic core hardware of the "Lick and Sitck" platform, e.g., the similar electronics. Chemical species gas sensors that have been integrated into this unit include two types of $\mathrm{CO}$ sensor, a $\mathrm{H}_{2} / \mathrm{H}_{\mathrm{x}} \mathrm{C}_{\mathrm{y}}$, a $\mathrm{CO}_{2}$ sensor, as well as humidity and pressure environmental sensors. A comparison of the size of the Miniaturized Multiparameter Smart Space Fire Detection System and the MMFDS is shown in 8b. A significant reduction in size is evident; however, it should be noted that the Miniaturized Multiparameter Smart Space Fire Detection System does not presently contain particulate detection capabilities available in the MMFDS. This feature is planned for later designs of the Space Fire Detection System. Testing of the Space Fire Detection System is ongoing to demonstrate the core capabilities of the MMFDS are maintained during the transition to the "Lick and Stick" hardware platform.

a)

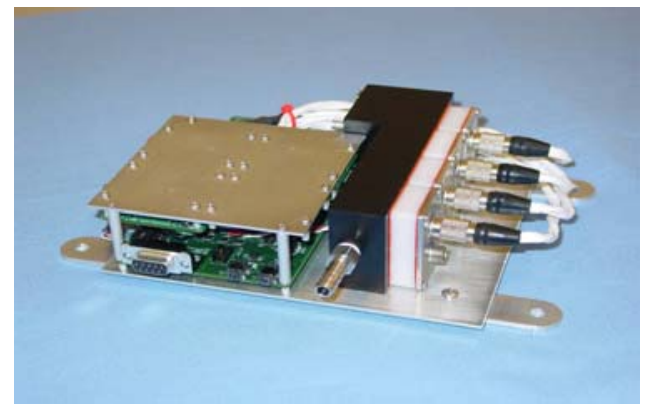

b)

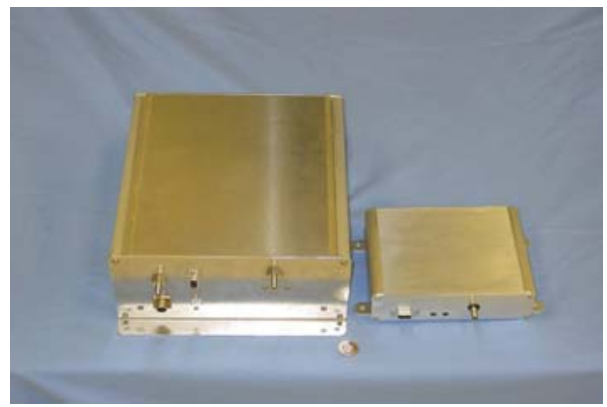

Figure 8. a) Picture of the Miniaturized Multiparameter Smart Space Fire Detection System. b) Comparison of MMFDS to the present version of the Miniaturized Multiparameter Smart Space Fire Detection System. The MMFDS dimensions are 10" x 10" x 4.50" compared with the newer systems with dimensions at 7.00” x 5.85” x 2.12”.

In summary, efforts are underway to transition a prototype aeronautics fire detection system to a design more compatible with implementation in space applications. This work has included transitioning the functionality of the aeronautics fire detection system into a hardware platform ("Lick and Stick" technology) already being qualified for space applications. This has resulted in decreasing the size of the aeronautics fire detection system and thus increasing its viability for space applications, but it also allows the use of a core hardware platform which has already shown the capability for possible space implementation.

\section{Extended System Testing: High Temperature Oxygen Sensor Evaluation for Inter- national Space Station Applications}

In order to qualify for hardware for implementation in an application requiring extended sensor calibration life, extensive testing is necessary. This is beyond the standard testing for radiation, shock, vibration, or thermal durability. Rather, this testing relates to the capability of the sensor system to reliably and accurately measure the environment as specified for the application. An example of these efforts relates to evaluation of oxygen 
sensor technology for application on the International Space Station (ISS) for environmental monitoring applications. Present liquid electrochemical cells currently deployed on the ISS do not this meet the accuracy or calibration life requirements. It is considered that a solid state sensor approach might be able to avoid some of the technology issues related to liquid based systems. However, one of the significant lessons learned related to sensor implementation on the ISS is the need for extensive relevant environmental and life testing.

In particular, zirconia $\left(\mathrm{ZrO}_{2}\right)$ based oxygen sensors in the "Lick and Stick" Smart Sensor platform were tested extensively. The design and operating principle of these higher temperature zirconia-based sensors is described elsewhere [7]. As seen in Figure 7, these oxygen sensors have already been integrated into the "Lick and Stick" platform; however, the units tested in this work include only a single channel for a single oxygen sensor. These single channel, "Lick and Stick" $\mathrm{O}_{2}$ sensor systems were tested extensively for their capability to accurately detect oxygen concentrations under various conditions at the White Sands Test Facilities (WSTF), as well as on a laboratory benchtop. The measurements of the sensors on the ISS are used in a critical safety application, so it is mandatory that sensors deployed in this application maintain calibration over multiple cycles for extended periods. The purpose of this testing is to determine the capability of the sensors in relevant operational conditions, as well determine sensor lifetime.

An example of some of the tests at WSTF is shown in Table 1. The approach is to duplicate the conditions seen during pressure cycles on the ISS during which the oxygen sensor must perform accurately. Thus, Table 1 shows testing which includes changing of $\mathrm{O}_{2}$ concentration along with pressure changes (dynamic) as well constant $\mathrm{O}_{2}$ concentrations in varying pressure conditions (static). The laboratory benchtop testing included operation of the sensor systems in laboratory conditions for extended periods to observe sensor drift and the affect of typical atmospheric contaminants.

Table 1. Descriptions of Sample Tests at the White Sands Test Facility.

\begin{tabular}{|c|l|l|}
\hline $\begin{array}{c}\text { Test/ } \\
\text { Steps }\end{array}$ & Double Dynamic & Static \\
\hline $\mathbf{1}$ & $\begin{array}{l}\text { Start with 18\% O2 at ambient pressure. } \\
\text { (Hold until stable) }\end{array}$ & $\begin{array}{l}\text { Start with 18\% O2 at ambient pressure (Hold until sta- } \\
\text { ble) }\end{array}$ \\
\hline $\mathbf{2}$ & $\begin{array}{l}\text { Hold 18\% O2 and increase pressure to } \\
\text { 14.7Psia: (Hold 6 minutes) }\end{array}$ & $\begin{array}{l}\text { Change O2 concentration to desired level while increas- } \\
\text { ing the pressure to 15.3Psia (Hold 6 } \\
\text { minutes) }\end{array}$ \\
\hline $\mathbf{3}$ & $\begin{array}{l}\text { Increase to 25\% O2 and decrease pressure } \\
\text { to 12Psia: (Hold 6 minutes) }\end{array}$ & $\begin{array}{l}\text { Keep the O2 concentration constant and decrease pres- } \\
\text { sure to 14.7Psia (Hold 6 minutes) }\end{array}$ \\
\hline $\mathbf{4}$ & $\begin{array}{l}\text { Increase to 28\% O2 and decrease pressure } \\
\text { to 10.2Psia (Hold 6 minutes) }\end{array}$ & $\begin{array}{l}\text { Keep the O2 concentration constant and decrease pres- } \\
\text { sure to 10.2Psia (Hold 6 minutes) }\end{array}$ \\
\hline $\mathbf{5}$ & $\begin{array}{l}\text { Decrease to 25\% O2 and increase pressure } \\
\text { to 14.7 Pisa (Hold 6 minutes) }\end{array}$ & $\begin{array}{l}\text { Keep the O2 concentration constant and decrease pres- } \\
\text { sure to 9.4Psia (Hold 6 minutes) }\end{array}$ \\
\hline $\mathbf{6}$ & The Double Dynamic test is complete & The Static test is complete \\
\hline
\end{tabular}

Data from both dynamic testing and static WSTF testing for the higher temperature $\mathrm{O}_{2}$ sensors testing is shown in Figure 9. The pressure, oxygen concentration, and the response of 5 high temperature oxygen sensors are shown. In each case, the sensors tracked the changes in oxygen concentration. Changes in pressure can affect the sensor output: these changes were compensated for by an on-board pressure sensor that measured the ambient pressure and allowed correction of the sensor output. The sensors held their calibration over multiple tests and were able to provide data within the calibration range required for the ISS environmental monitoring application. Furthermore, the response of 
the sensors stayed consistent for extended periods and were seemingly unaffected by the various testing. Shown in Figure 10 is data from continuous benchtop operation for the same five sensors. The data shows consistent and stable operation while being exposed to the ambient environment. While "spikes" in the data are noted, the sensors consistently gave stable readings for extended periods.

\section{a)}

Figure 9. Response of a Higher Temperature Zirconia Oxygen Sensor in a "Lick and Stick" platform during a) Dynamic Test and b) Static Test. These tests are used to evaluate sensor behavior for possible implementation on an ISS environmental monitoring applications.

b)
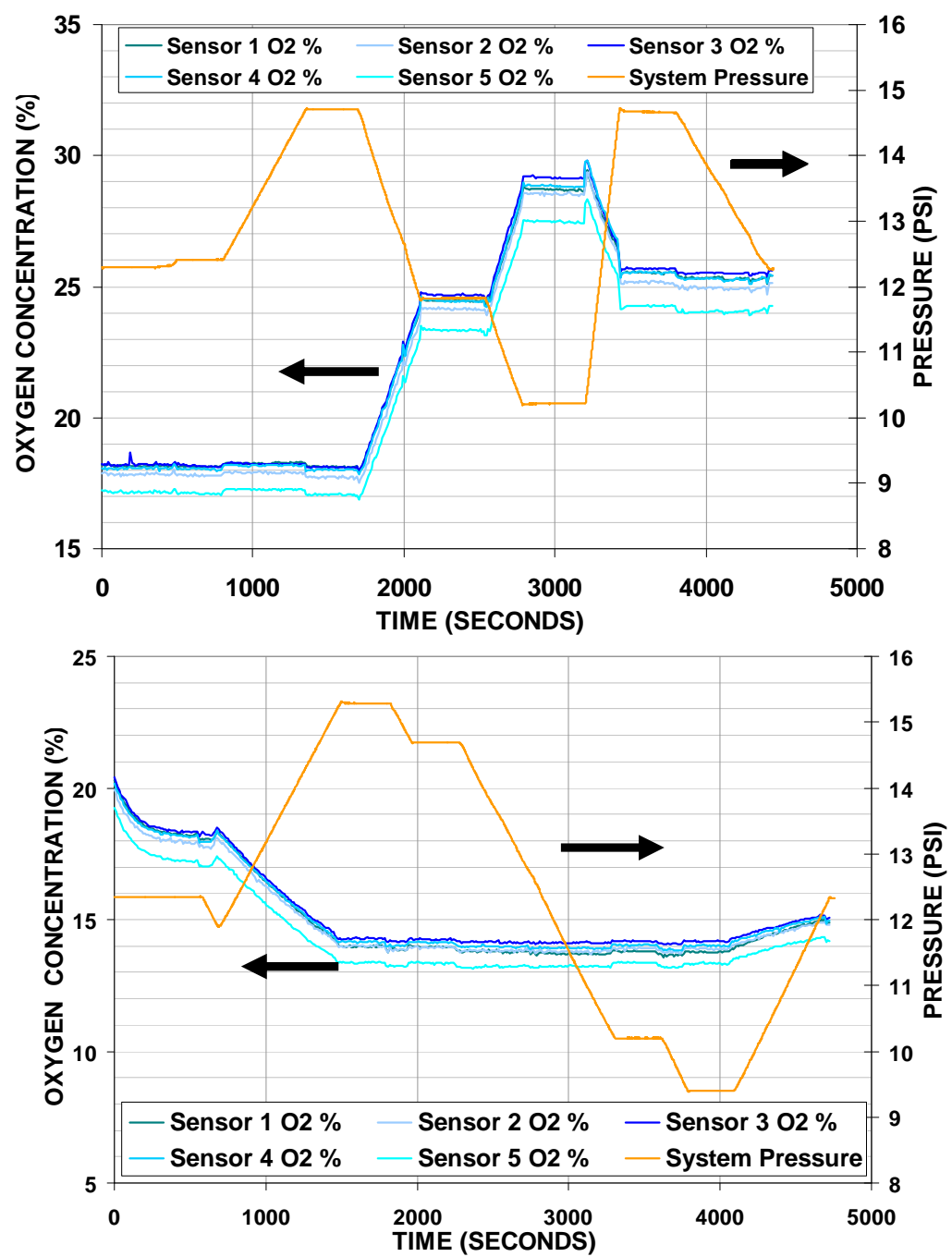

The culmination of this testing has been over 2 years of benchtop operation and testing in ambient environments, as well as the equivalent of eight years of pressure cycle operation on the ISS. The conclusion of this testing is that the high temperature $\mathrm{O}_{2}$ sensors with associated hardware continue to operate within specifications and their performance characteristics are appropriate for this ISS application. However, a barrier to implementation of these sensors is the power consumption associated with the sensors (on the order of $200 \mathrm{~mW}$ for each sensor). For these sensors to be portable on ISS, they must be battery powered. Such a power consumption as $200 \mathrm{~mW}$ or more for each sensor in continuous operation will require bi-weekly battery replacements. This is an issue because of the limit amount of available crew time and limited upmass for battery delivery. Rechargable batteries have been considered but this increases the required crew time. Thus, development of low powered, room temperature oxygen sensor systems continues.

In summary, extended testing has occurred to understand the properties of a zirconia based oxygen sensor in a "Lick and Stick" sensor platform. This type of testing is a sig- 
nificant component of gaining confidence in the performance of the sensor system, and is beyond the basic testing of the sensor for vibration, thermal, etc. that is traditionally part of space qualification. This extended testing has resulted in a determination that the sensor system is ready for application for this particular ISS environmental monitoring application.

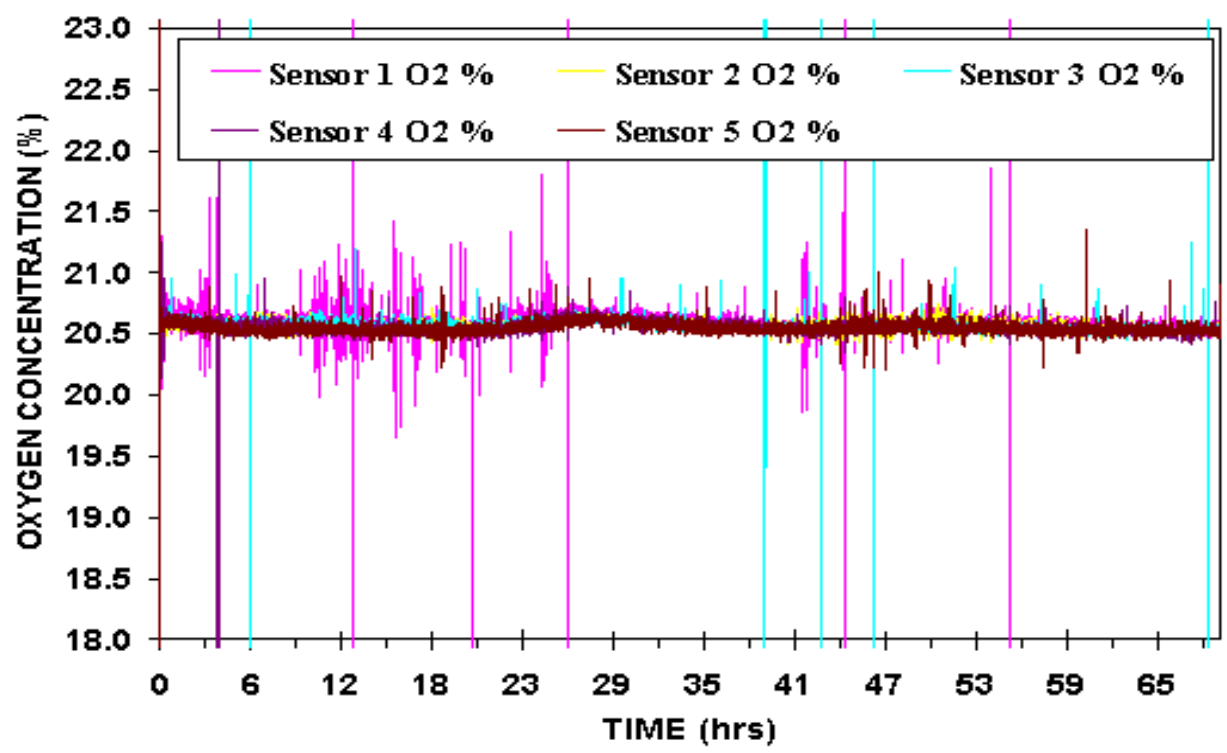

Figure 10. Zirconia sensor response during bench top testing over a multi-day span.

\section{Summary and Conclusions}

This paper describes activities of relevance for multiple aerospace applications: 1) The broadening of sensitivity and operational range of the silicon carbide (SiC) Schottky sensor system; 2) Integration of fire detection sensor technology into a "Lick and Stick" Smart Sensor platform for Crew Exploration Vehicle applications; 3) Extended testing for zirconia based oxygen sensors in the basic "Lick and Stick" platform for environmental monitoring applications. The results of this work showed that the SiC Schottky diode sensor had a wide range of capability, but knowledge of the sensor characteristics is necessary to take advantage of these properties. Implementation of this type of sensor into space flight systems first requires that the hardware be designed for such applications and that the complete system undergo extensive testing. Description of the transition of an aeronautics fire detection system into "Lick and Stick" hardware, and the testing of that hardware platform with an oxygen sensor for possible ISS implementation provides examples of some of the development steps necessary for sensor system developments.

Overall, the development of Smart Sensor Systems for flight implementation is a multistage, multidisciplinary process that involves: 1 ) Tailored sensor development to meet the needs of the application; 2) Integration of sensors into hardware that is appropriate for flight applications and integration with the specific vehicle application; and 3) Extensive testing of the resulting system to verify not only its flight capability but also its capability to meet the performance requirements of the application.

However, one of the fundamental suggestions implied by this paper is that sensor platform technology combined with a basic hardware platform (e.g. "Lick and Stick" 
technology) can enhance the viability of implementing Smart Sensor Systems in aerospace applications if they are chosen properly in the development stage. The approach is to work from this core technology base and adapt the Smart Sensor Systems to a range of applications. This is one of the advantages of Smart Sensor Systems: the ability to program new functions into processors and swap out module boards within the system allows a wide range of adaptability. If the core technology of sensors and hardware are viable for aerospace applications, then meeting the needs of an individual application is achievable from this core through further targeted development and adaptation of the system.

\section{Acknowledgements}

The authors gratefully acknowledge the contributions of those who made this paper and its contents possible: Dr. G. Ruff, Dr. L. Matus, G. Fralick, and C. Swanson of NASA GRC; D. Lukco of ASRC/NASA; M. Artale, P. Lampard, C. Hampton, D. Androjna, and B. Osborn of Sierra Lobo; the staff at the White Sands Test Facility, and L. Dudik of CWRU.

\section{References}

1. G. W. Hunter. J. C. Xu, and D. B. Makel, "Case Studies in Chemical Sensor Development”, Chapter 8, in BioNanoFluidic MEMS, P. Hesketh Ed. Springer Press, New York, NY, (2007).

2. G. W. Hunter, J. C. Xu, C. C. Liu, and D. B. Makel, in The MEMS Handbook Second Edition: Design and Fabrication, M. Gad-El-Hak, Editor, Chapter 11, CRC Press, Baton Rouge (2006).

3. G. W. Hunter, P. G. Neudeck, J. Xu, D. Lukco, A. Trunek, M. Artale, P. Lampard, D. Androjna, D. Makel, B. Ward, and C. C. Liu, "Development of SiC-based Gas Sensors for Aerospace Applications”, in Silicon Carbide 2004-Materials Processing and Devices, edited by M. Dudley, P. Gouma, T. Kimoto, P. G. Neudeck, and S. E. Saddow (Mater. Res. Soc. Symp. Proc. 815, Warrendale, PA , 2004) Materials Research Society Symposium Proceedings Series, pg. 287-298.

4. G. W. Hunter, J. Xu, P. G. Neudeck, D. Lukco, A. Trunek, D. Spry, M. Artale, P. Lampard, D. Androjna, D. Makel and B. Ward, "Silicon Carbide Gas Sensors For Propulsion Emissions And Safety Applications”, Proceedings of the 54th Joint Propulsion Meeting , JANNAF, , Denver CO, May, 2007

5. G. W. Hunter, L. G. Oberle, G. Baakalini, J. Perotti, and T. Hong, "Intelligent Sensor Systems for Integrated System Health Management in Exploration Application”, Proveedings of the First International Forum on Integrated System Health Engineering and Management in Aerospace, November, 2005.

6. G. W. Hunter, P. G. Neudeck, G. Fralick, D. Makel, C. C. Liu, B. Ward, Q. H. Wu, V. Thomas, and G Hall, "Microfabricated Chemical Sensors for Space Health Monitoring Applications”, AIAA Space 2001 Conference, August 2001, Albuquerque, NM, AIAA 2001-4689, 2001.

7. G. W. Hunter, J. C. Xu, P. G. Neudeck,D. B. Makel, B. Ward and C. C. Liu "Intelligent Chemical Sensor Systems For In-Space Safety Applications”, 42nd AIAA/ASME/SAE/ASEE Joint Propulsion Conference And Exhibit, Sacramento, CA, 9-12 July 2006, Paper AIAA-2006-4356. 